\title{
An Empirical Study of Online Consumer Behavior for Apparel \&t Electronics Segment
}

\author{
Harish Kumar S. Purohit and Abhishek S. Deokule \\ ${ }^{1}$ Parle TilakVidyalaya Association's Institute of Management \\ (Affiliated to University of Mumbai), Maharashtra, India \\ ${ }^{2}$ Marketing, Parle TilakVidyalaya Association's Institute of Management \\ (Affiliated to University of Mumbai), Maharashtra, India
}

\begin{abstract}
With the advent of internet and e-commerce the face of shopping has evolved in India. Not only are consumers buying online like never before but their behavioral traits while shopping online is an area which has always perplexed marketing researchers. The research work carried out in this paper primarily comprises of understanding and assessing consumers shopping patterns with specific reference to apparel and electronic category and the parameters which consumers evaluate before buying and post purchase leading to repurchase intentions. The study distinctively uses statistical techniques to differentiate buyers as per demography and unravels factors such as comfort, trust,convenience, time and ease of use to buy apparel and electronic products online. Display of products in an E-commerce set up is also looked up by many consumers as well as comparison between price points and delivery time are some of the key reasons elicited in this study. Apart from these, psychographic traits of consumers are explored for planned purchases and has a wide scope of research.
\end{abstract}

KEY WORDS: ONLINE SHOPPING, ONLINE CONSUMER BEHAVIOR, E-COMMERCE, APPARELS \& ELECTRONICS, INDIAN MARKETS.

\section{INTRODUCTION}

Shopping seem to be an important aspect of Indian culture, so Indian consumer perceived with different context. The journey has begun from weekly bazar \& come to a stage of E-commerce. Ecommerce is evolving industry in India. Development \&t prior understanding has helped them to drive business.

\section{Factors propelling the growth of E-Commerce}

\footnotetext{
Biosc Biotech Res Comm P-ISSN: 0974-6455 E-ISSN: 2321-4007 Index by Thomson Reuters ISI Web of Science Clarivate Analytics USA Identifiers and Pagination Article Information Year: 2021 Vol: 14 No (5) Received: $17^{\text {th }}$ Jan 2021 Special Issue Pages: 113-117 Accepted after revision: $28^{\text {th }}$ Mar 2021

This is an open access article under a Creative Commons License Attribn 4.0 Intl (CC-BY). DOI: $h t t p: / / d x$.doi.org/10.21786/bbrc/14.5/22
}

1. Accessibility to Internet.

2. Advancement in Smart-phone industry to grab the shopping.

3. Smaller towns don't have exposure towards the Branded products, so online provide exposure towards it.

4. Advancement in Logistics, international as well as domestic.

5. Metro people lifestyle has changed, busy schedule has made them look for fast, quality, customized \& all-products based kind shopping approach.

6. Market size is huge, scope for growth \&t attending same customer

7. (Internet user-base is at 500-odd million Internet users (in 2020). (IAMAI)

Review of Literature: Consumer behaviour is a simple yet complex phenomenon. The amount of spends that happen on online shopping has changed ever since the proliferation of E-commerce payers and Internet

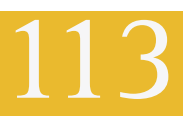


penetration. Although it is different than shopping offline there are certain set theories and framework that hold true for both the modes of shopping. Theory of planned behavior (TPB) is a one such potent theory within an expectancy value frame work, but also a social theory which enumerates the human decision process which eventually leads to buying.

TPB suggest that human behavior decision making is partly under the control of the people concerned. Thus, adding the determinant of uncertain time, uncertain opportunity the so called Perceived Behavioral Control factor such factors can affect indirectly. Wang (2007) suggests that given the differences between a simulated and a traditional marketplace, antecedents and consequences of trust needs re-examination. The findings from research suggest that people are more likely to purchase from the web if they perceive a higher degree of trust in e-commerce and have more experience in using the web. Customer's trust levels are likely to be influenced by the level of perceived market orientation, website quality, technical fluidity, trustworthiness, and user's web engagement experience. People with a higher level of perceived site quality seem to have a higher level of perceived market orientation and trustworthiness .

towards e- commerce. (Corbitt, Thanasankit, Yi, 2003) Purchase decision is often influenced by exciting offers, services, innovativeness, discounts, layout and offerings. It has suggested that psychographic traits affect consumer's likeability and propensity to purchase also called as deal-proneness behaviour. Deal proneness is associated with price consciousness and is also affected by other consumer traits Such as innovativeness, impulsiveness and shopping enjoyment. Deal proneness is domain specific, and consumers respond to certain type of promotions while ignoring others. Deal-prone consumers generate more positive word of mouth than firm's satisfied consumers. Firms should target incentive programmes to loyal consumers, as it is likely to affect sales and add to consumer base. Dynamic deal proneness refers to sensitivity towards features of different types of coupons. It would imply actively searching about different coupons. (Khare) opines that passive deal proneness is characterized by being sensitive to in-store displays. The search is limited to a specific environment like a website offering gadgets, apparel, groceries etc.

Research Objectives: A brief understanding about consumer behavior for online shopping industry is seen to be as need of time. Our research work will focus majorly on how consumers behave in the given scenario. The sample size chosen for our study is 50 which is representative of the large population of consumers who buy online. As only higher NCCS has seen with online shopping, our focus on TG with 20-34 AB. It has considered in link with spread has considered with top 8 metros functioning with online shopping. Target group indexes provides the related target definition to arrive at the right level.

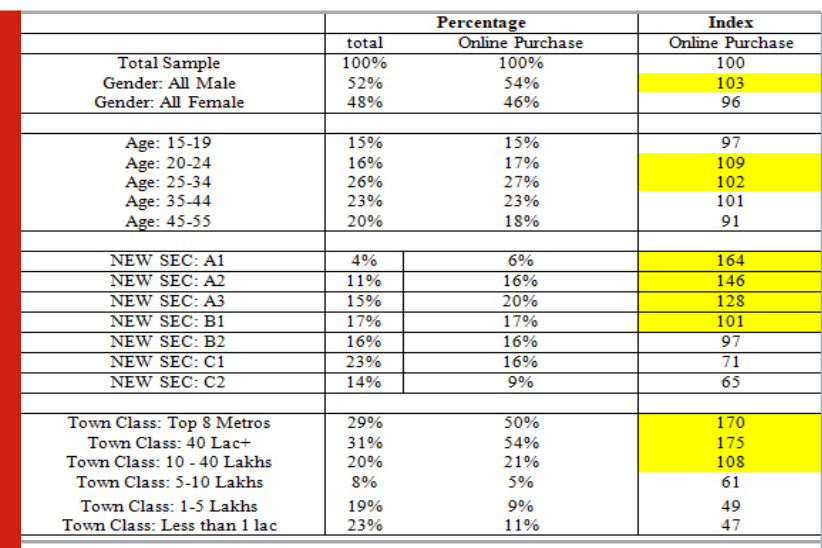

Source -Target Group Index Survey 2019 by IMRB

\section{Data Analysis \&t Interpretation: Demographic Details:}

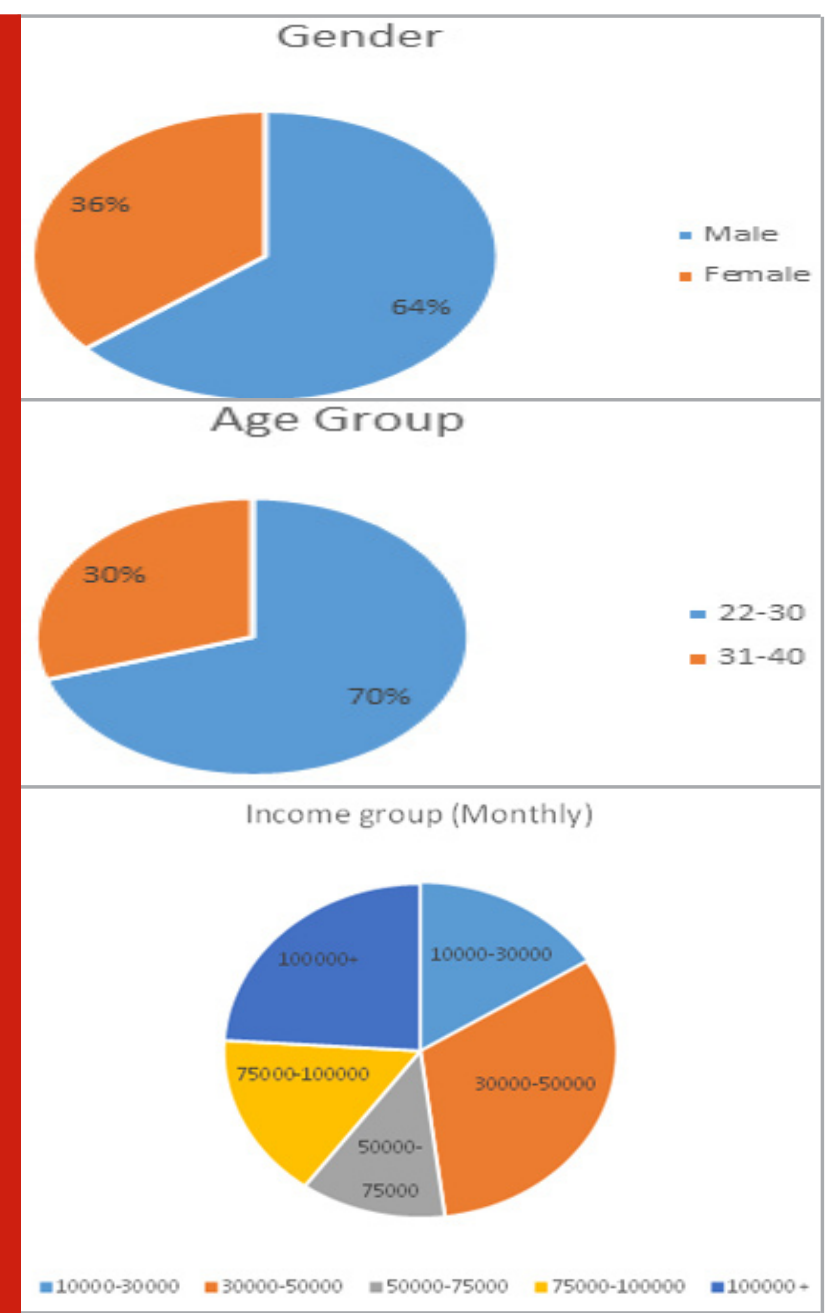

\section{a. Hypothesis Testing :}

H01: People are looking only for comfort now-a-days, especially when it comes to shopping.

Calculated value is 0.262 Table value -7.89

As table value $>$ calculated value, we should accept the null hypothesis. So now a day's people are looking-up 
for comfort in the shopping.

H02: Product presentation has valued more than anyother thing to get sold.

\begin{tabular}{|c|c|c|c|}
\hline 0 & $E$ & $(0-E)^{\wedge} 2$ & $(0-E) \wedge 2 / E$ \\
\hline 22 & 21.5 & 0.25 & 0.012 \\
\hline 32 & 29.6 & 5.76 & 0.195 \\
\hline 18 & 17.5 & 0.25 & 0.014 \\
\hline 23 & 24 & 1.00 & 0.042 \\
\hline & & & 0.262 \\
\hline
\end{tabular}

\begin{tabular}{|c|c|c|c|}
\hline 0 & $E$ & $(0-E) \wedge 2$ & $(0-E) \wedge 2 / E$ \\
\hline 33 & 39 & 36.00 & 0.923 \\
\hline 34 & 36 & 4.00 & 0.111 \\
\hline 41 & 43 & 4.00 & 0.093 \\
\hline 42 & 41 & 1.00 & 0.024 \\
\hline & & & 1.152 \\
\hline
\end{tabular}

\begin{tabular}{|c|c|c|c|}
\hline 0 & $\mathrm{E}$ & $(0-\mathrm{E})^{\wedge} 2$ & $(0-\mathrm{E})^{\wedge} 2 / \mathrm{E}$ \\
\hline 38 & 42 & 16.00 & 0.381 \\
\hline 36 & 44 & 64.00 & 1.455 \\
\hline 35 & 41 & 36.00 & 0.878 \\
\hline 39 & 40 & 1.00 & 0.025 \\
\hline & & & 2.739 \\
\hline
\end{tabular}

Calculated value is 1.152 Table value -7.89

As table value $>$ calculated value, we should accept the null hypothesis. So, product presentation matters a lot when it comes to the shopping.

H03: Online shopping is self-driven, unlike offline where influencers can make a difference.

Calculated value is 2.739 Table value -7.89

As table value $>$ calculated value, we should accept the null hypothesis.

So online shopping is self -driven \& there are lesser / no influencers for this shopping.

\section{b. Pareto Analysis}

To understand for what consumer is looking for.

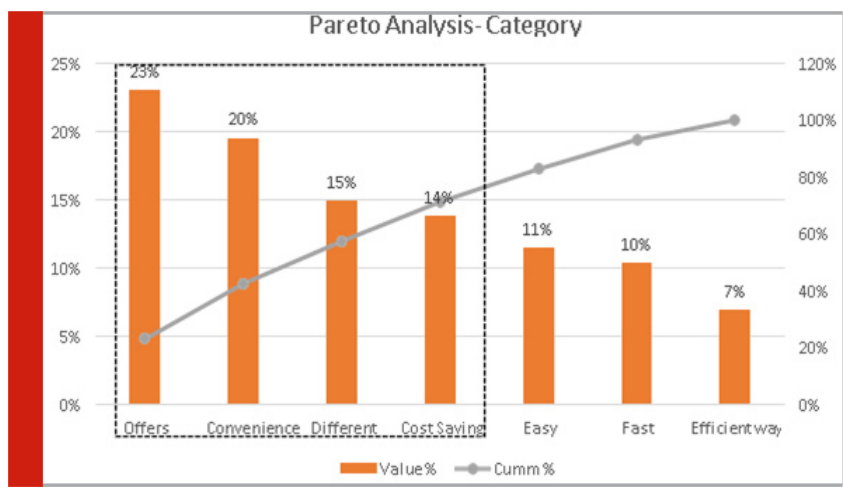

- This showcase that around 75\% of consumers are preferring E-Commerce as Category-Offers, Convenience, Different, Cost Saving.

- Category has seen with convenience, offers \& budgeted product selling.

- It is more life-style based approach for e-commerce shopping. Such as busy schedules, working hours \&t convenient way.

- Brand working is associated with Well presentation, exclusively available, able to distinguish \& Trust build by the brand.

- Presentation \& Exclusivity drives maximum value in the consumer's mind, when it comes to buying from particular online-portal.

- Still differentiated positioning is something requirement of the hour, to make loyal base \&t create unique brand identity in the market.

- $\quad$ Cookie driven offering (recommendation by site); payment options seem to be saturated as it is getting all sites choices.

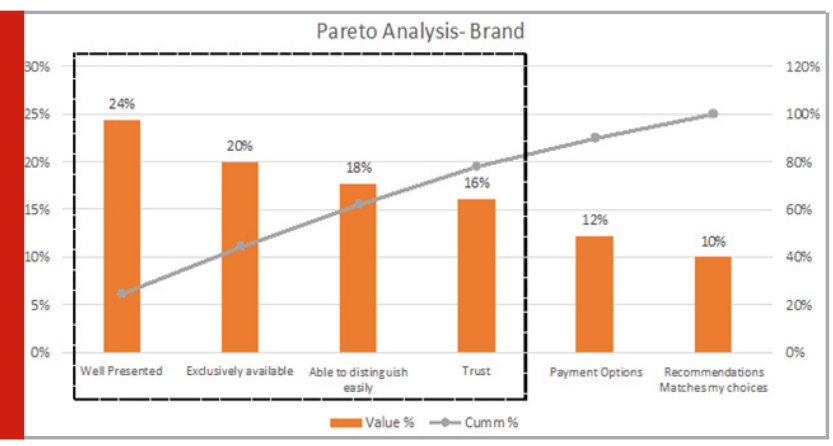

\section{c. Cross-tab Analysis}

To grab-up what is getting more established with different consumer demographics with buyer behavior.

1. Online Shopping frequency, age -group, to understand does the buying freq. changes with age-group or not.

\begin{tabular}{|l|c|c|}
\hline \multirow{2}{*}{ Online Shopping freq. } & \multicolumn{2}{|c|}{ Age-group } \\
\cline { 2 - 3 } & $22-30$ & $31-40$ \\
\hline \multirow{2}{*}{ Once a Week } & $9 \%$ & $20 \%$ \\
\hline Once a month & $34 \%$ & $33 \%$ \\
\hline Once in 3 months & $31 \%$ & $20 \%$ \\
\hline Once in 6 months & $26 \%$ & $20 \%$ \\
\hline Once in year & $0 \%$ & $7 \%$ \\
\hline
\end{tabular}

\begin{tabular}{|l|c|c|}
\multirow{2}{*}{ Price Range for Shopping } & \multicolumn{2}{|c|}{ Age-group } \\
\cline { 2 - 3 } & $22-30$ & $31-40$ \\
\hline \multirow{2}{*}{ Below 10,000} & $69 \%$ & $47 \%$ \\
\hline $10,000-25,000$ & $29 \%$ & $33 \%$ \\
\hline $25,000-50,000$ & $3 \%$ & $20 \%$ \\
\hline
\end{tabular}

- It showcases that a month to 3 months is freq. is seen to be large chunk opt for, it may be also driven by offers/Bonanza created by each online portal to make-up in quarterly levels. 
- $\quad$ Older age-group (31-40) has smaller chunk which goes for regular for buying online.

2.0nline shopping price point considerations - with age -group.

- Below $10 \mathrm{~K}$ is safest price range, what people are looking for smaller segments more.

- But as a Business practice, we can say that below 25K is range of products covers $90 \%$ of young consumers At $80 \%$ for older consumer.

- Higher price range is something related to income range also, higher Age group can be tapped for big price deals also.

3.Price point consideration vs. Time taken for decision making -

- For a mid-range buyer, we can see that it takes majorly 1-6 hrs. to finalize the buying decision on online medium.

- As compared to higher price range where more complexities, specification involved then it takes more times, hence time involvement has seen fragmented $\&$ subjective.

\begin{tabular}{|c|c|c|c|}
\hline \multirow{2}{*}{ Time taken for decision } & \multicolumn{3}{|c|}{ Consideration of Price } \\
\cline { 2 - 4 } & Below 10,000 & $\mathbf{1 0 , 0 0 0 - 2 5 , 0 0 0}$ & $\mathbf{2 5 , 0 0 0 - 5 0 , 0 0 0}$ \\
\hline Less than 1 hr. & $25 \%$ & $27 \%$ & $25 \%$ \\
\hline 1 hr. $-6 \mathrm{hr}$. & $38 \%$ & $20 \%$ & $25 \%$ \\
\hline 6 hr. $-24 \mathrm{hr}$. & $9 \%$ & $13 \%$ & $25 \%$ \\
\hline 1 day -3 days & $9 \%$ & $7 \%$ & - \\
\hline 3 days -1 week & $16 \%$ & $27 \%$ & - \\
\hline More than 1 week & $3 \%$ & $7 \%$ & $25 \%$ \\
\hline
\end{tabular}

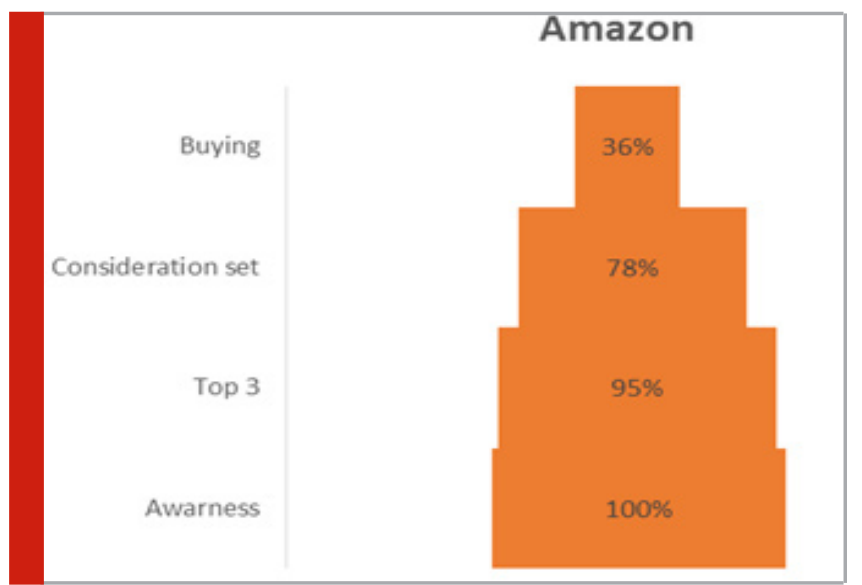

\begin{tabular}{|l|c|c|}
\hline & Segment 1 & Segment 2 \\
\hline Buying freq. & 0.636 & 1.356 \\
\hline Time Taken & 1.359 & 0.495 \\
\hline Value Consideration & 0.665 & 1.445 \\
\hline Influence & 0.659 & 0.8826 \\
\hline Impulse Buyer & 0.894 & 1.365 \\
\hline Electronics & 1.645 & 0.956 \\
\hline Age & $22-30$ & $31-40$ \\
\hline Income & $10 \mathrm{k}-30 \mathrm{k}$ & $40 \mathrm{k}-75 \mathrm{k}$ \\
\hline
\end{tabular}

\section{d. Consumer Buying Pyramid-}

Awareness - Purchase model will help us understand the consumer journey towards particular brand. As there are two big players in the market Amazon \&t Flipkart, let see their model in detail.

- There is $100 \%$ awareness about the brand, people often refer this one with category itself.

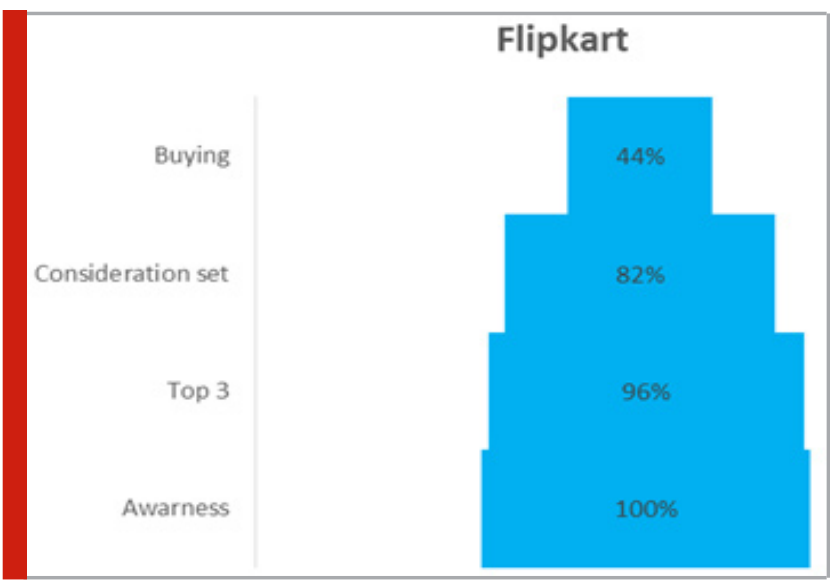

- In the presence of top 3 is also very high, hardly 5\% drop seen in the second level, while for consideration set it goes to 78\% for thinking of shopping.

- Consideration may get driven by offers, exclusive availability etc.

- $\quad$ Final buyers will be 36\% among all, which is almost becomes half of consideration set. Buying decision has attached with more points.

- It has seen with category level only, as awareness is $100 \%$, continuing with development of category is lead-in for Flip-kart.

- Top 3, which is top of the mind consideration has seen 4\% drop only. Where-as in Consideration set for buying has seen 14\% drop. Competition offers, fragmented market on categories has made this level drop.

- Buying decision has makes them drop by 50\% around, this is sheer outcome of increase in competition, offers \& segmented markets.

\section{e. Cluster analysis}

From above analysis we have realized that there are 
two type of customers exist in the market, we can do segmentation analysis to understand them thoroughly.

1. A Young 22-30 age group, looking for offer $\&$ consumer who is also tech-savvy.

2. A Mid Age-group 31-40, looking for comfort \&t who is going for higher price range also.

A matrix based on different variables showcases the case for cluster analysis \& factors which are having higher weightage.

\section{Limitations}

1. A major limitation of the project is real time data for Analysis. (Traffic Analysis)

- It would provide how consumer understands, surf Et come for the buying of the product. On online medium.

- It will generate more accuracy in results, as it is based on actual /real time data base.

2. Deep Psychographic study for online shopping need to be taken, as it will enhance the level of future workouts.

- $\quad$ Psychographic study will help us to create a rationale behind the various decision taken by consumers for buying product.

- $\quad$ Any Future development will make easy to have deep knowledge about online shopping psychograph.

Recommendations: As analysis of surveyed data, secondary sources understanding \& expert review will help us arrive at a common thread consumer behavior which we can propel in-terms of consumer behavior under e- commerce medium. As we have restricted our study to Electronics \& Apparel, it would more implied for them. A recommendation would be useful to those who are entering newly in the market \&t existing once also as they as looking-up for -

\section{- Self-engaging Links -}

- More than 90\% of consumers are buying the products based on self-assessment, there is no influence of others.

- It makes the consumers to step-up \& go for buying without any pre-assumptions of anybody.

- Enhancing user experience -

- Interface use enhancement is a crucial in terms of selection on functional \&t emotional basis.

- Making user friendly, self-explanatory \&t well offer description portal to keeping \& enhancing the comfort mode.

- $\quad$ Building Loyal customer base -

- As category specific offerings, customer value programmes are taken-up by various brands \&t also increased competition in the market, makes consumer loyalty programme to enhance the core buyer base.

- Online buying is either by niche or by community buying.

- Making advertising use for making portal into the consideration of top 3 (TOM), so the higher sales could be achieved. Developing Online buying as a ritual -

- As on many occasions in India there is shopping is a ritual, it can get synchronized with online shopping. Helping \& deriving value.

- Creating impulse bid for consumer shopping behavior, as there is strong trend which is making a comfort base shopping a regular.

\section{CONCLUSION}

Conclusion will ultimately answer the objective that we are looking for, Consumer behavior has changed, when it comes to online shopping. In modern day in India, we have seen urban life-style has changed, there is generation who is busy with office work, has money to spend on (Urban NI increased by $40 \%$ in last decade) , cultural changes has observed by Indian's, the new way of shopping has given birth to it 'E-commerce'. Shopping perception has also observed a change.

Giving the clear sense of following things in online buying will make the suitable on -

3. Steps in making the buying decision, which has become complex $\&$ subjective in nature for online buying.

4. Change of Planned to Impulse buying decision in many products.

a. It is self-driven buying behavior; it has lesser impact of externalities.

b. Role of presentation make buyer to buy it, which also could be experience part to make change from planned to impulse.

5. Two type of segments exist; in which we can broadly classify the consumers.

a. Young buyers looking for Tech-savvy products, has mid-price range option.

b. Mid age buyers looking for comfort majorly, has high price range.

\section{REFERENCES}

Gong,W.Stump,R.L. and Maddox,L.M.(2013)‘Factors influencing consumers' online shopping in China', Journal of Asia Business Studies,7(3),p214-230.

Jones, K., Leonard,NL.N.K.(2007) 'C onsumerto-Consumer Electronic Commerce: A Distinct Research Stream', Journal of Electronic Commerce in Organizations,5(4),p39-54.

Sapna,R.Khare,A.(2012)'Impact of promotions and value consciousness in online shopping behaviour in India', Journal of Database Marketing \& C Customer Strategy Management,19(4),p311-320.

Suki,N.M.,Suki,N.M.(2007)'Online Buying Innovativeness: Effects of Perceived Value, Perceived Risk and Perceived Enjoyment', Journal of Business and Society,8(2),p81-93.

Wang,M.S.,Chung,C. ,Su-Chao, C., Yang.Y.H. (2007)'Effects of Online Shopping Attitudes, Subjective Norms and Control Beliefs on Online Shopping Intentions: A Test of the Theory of Planned Behaviour', International Journal of Management,24(2),p296-302 Kalkota, R. and Robinson. (2004) E-Business.2nd edn. Subramani,N.,Murugesan,M.,Anbalagan,D. and Ganesan,V.(2009) E-banking \&t E- commerce emerging issues in India. 